\title{
Tuberculosis infection among youths in overcrowded university hostels in Kenya: a cross-sectional study
}

\author{
Teresia Maina ${ }^{1}\left(\mathbb{D}\right.$, Annie Willetts ${ }^{2}$, Moses Ngari ${ }^{1,3}$ and Abdullahi Osman ${ }^{1 *}$ (D)
}

\begin{abstract}
Background: Tuberculosis (TB) remains a top global health problem and its transmission rate among contacts is higher when they are cohabiting with a person who is sputum smear-positive. Our study aimed to describe the prevalence of TB among student contacts in the university and determine factors associated with TB transmission.

Methods: We performed a cross-sectional study with an active contact case finding approach among students receiving treatment at Kilifi County Hospital from January 2016 to December 2017. The study was conducted in a public university in Kilifi County, a rural area within the resource-limited context of Kenya. The study population included students attending the university and identified as sharing accommodation or off-campus hostels, or a close social contact to an index case. The index case was defined as a fellow university student diagnosed with TB at the Kilifi County Hospital during the study period. Contacts were traced and tested for TB using GeneXpert.
\end{abstract}

Results: Among the 57 eligible index students identified, 51 (89\%) agreed to participate. A total of 156 student contacts were recruited, screened and provided a sputum sample. The prevalence of TB (GeneXpert test positive/clinical diagnosis) among all contacts was 8.3\% (95\% Cl 4.5-14\%). Among the 8.3\% testing positive 3.2\% (95\% Cl 1.0-7.3\%) were positive for GeneXpert only. Sharing a bed with an index case was the only factor significantly associated with TB infection. No other demographic or clinical factor was associated with TB infection.

Conclusion: Our study identified a high level of TB transmission among university students who had contact with the index cases. The study justifies further research to explore the genetic sequence and magnitude of TB transmission among students in overcrowded university in resource limited contexts.

Keywords: Contact investigation, University students, Index cases, Clinical TB, GeneXpert, Tuberculosis

\section{Introduction}

Tuberculosis (TB) is among the top ten causes of death globally from a single infectious agent, ranking higher than HIV/AIDS [1]. In 2019, an estimated 10 million people became infected with $\mathrm{TB}$ and 1.4 million succumbed to the disease [1]. TB affects people of all age groups, however the burden of the infection shifted

*Correspondence: o.abdullahi@pu.ac.ke

1 Department of Public Health, School of Health and Human Sciences, Pwani University, P.O Box 196-80108, Kilifi, Kenya

Full list of author information is available at the end of the article more recently to the young adult population who form the economically productive people in a society. A global estimate of TB prevalence among young adults aged 15-24 years in 2012 found 1.78 million young adults had contracted TB [2]. Among the limited studies conducted with young adults reported, and barriers attributed to testing and treatment include stigma, perception of TB, knowledge about illness and availability of diagnostic tests, in addition to broader health system challenges of access to care [3-5]. These barriers in TB diagnosis and treatment further exacerbate the TB burden among the young adult population. 
Active contact investigation in high-income countries with low disease burden is a strategy implemented to rapidly identify persons with active or latent TB. Within a resource-limited setting, active contact-tracing strategies are routinely included in the national TB control and prevention programmes, however implementation is rare or inconsistent, partly contributed by a lack of clear definitions of index cases, contacts and contact-tracing procedures [6]. Resource-limited settings rely on passive contact tracing among people who present themselves to health services with TB symptoms. Studies however report tracing among household contacts identify more TB cases than passive case finding approach $[7,8]$. A systematic review and meta-analysis involving 95 contact investigation studies from resource-limited countries showed a $3.1 \%$ prevalence of TB among household contacts with the highest incidence occurring in the first 12 months after exposure [9]. In a resource-limited context adopting an active case finding strategy however targeting high-risk populations for TB provides a more feasible approach to reduce transmission.

Studies conducted in congregate settings have observed that overcrowding, poor ventilation, psychosocial factors and close contact with TB patients for extended duration [9-11] contribute to TB transmission among high-risk groups. In tertiary learning institutions, a single student with TB disease has numerous close contacts highlighting both the potential for transmission and potential for active disease or latent infections [12]. A study conducted at the Addis Ababa University, Sidist Kilo campus and the Adama Science and Technology University reported a prevalence of 511.7/100,000 and 1098.1/100,000, respectively [13]. The university context potentially presents a high burden of TB infection and transmission among the student population.

Kenya is among the 30 countries with a high TB disease burden [1]. The recent national prevalence survey of pulmonary TB in Kenya conducted in 2016 for people above the age of 15 years found 558 per 100,000, of which $16.7 \%$ were co-infected with HIV [14]. In the national survey of 2016 , only $6 / 305(2.0 \%)$ TB cases were confirmed to have rifampicin resistance [14]. There is limited data on TB transmission among university students in Kenya. This study aimed to describe the prevalence of TB among student contacts in the university and determine factors associated with TB transmission.

\section{Methods}

\section{Settings and participants}

The study was set in Kilifi County which is located on the coast of Kenya. Kilifi has an estimated population of 1.4 million (national: 43 million) and approximately $74 \%$ of people reside in rural areas of this county [15].
Subsistence farming is the main economic activity. In 2017, HIV prevalence in Kilifi County was 3.8\% (national $4.8 \%$ ) and $86 \%$ of children had received the BCG (Bacillus Calmette-Guérin) vaccine in 2016 [16]. Our participants were all young adults attending a public university located in Kilifi Town. The total population of students within the university was 8,600 during the study period. All university students residing in hostels within the campus and off-campus were eligible to participate in this study. The university hostels are supplied with bunk beds accommodating two to four students per room. Due to limited accommodation within campus about $90 \%$ of the students reside off-campus in hostels within a 3-km radius from the university. Over-crowding within the off-campus facilities is common when students resort to sharing facilities, including beds, within the small rooms. A university health facility is located within the campus, however clinic staff routinely refer students suspected to have TB to the nearest diagnostic centre at Kilifi County Hospital $(\mathrm{KCH})$, located within $2-\mathrm{km}$ radius from the university.

All students receiving TB treatment at the county hospital from January 2016 to December 2017 were invited to participate in this study following a detailed explanation of the purpose, benefit and risks associated with recruitment. To ensure all students with TB are included, the study recruited index students with both pulmonary and extrapulmonary TB, including those living with HIV [18]. A household contact was defined as a person sharing an enclosed living space (hostel) with an index case for one or more nights or for frequent periods during the 3 months before commencing anti-TB treatment. A social contact was defined as a person not in the same hostel as an index case, however as described sharing an enclosed space such as lecture hall, dining area or library for extended periods during the day in the previous 3 months before TB treatment initiated.

\section{Study design}

We conducted a cross-sectional study with an active case finding approach among student indexes registered at $\mathrm{KCH}$ from January 2016 to December 2017 to identify students diagnosed with TB. The index cases were recruited at different stages of their treatment. We used a trace-and-test approach accompanied by rapid testing using GeneXpert to identify cases infected with TB.

\section{Trace-and-test approach}

We conducted a TB contact active case-finding approach as illustrated in Fig. 1. The multi-step process involved use of mobile phones to trace both indexes and their contacts as summarised below. 


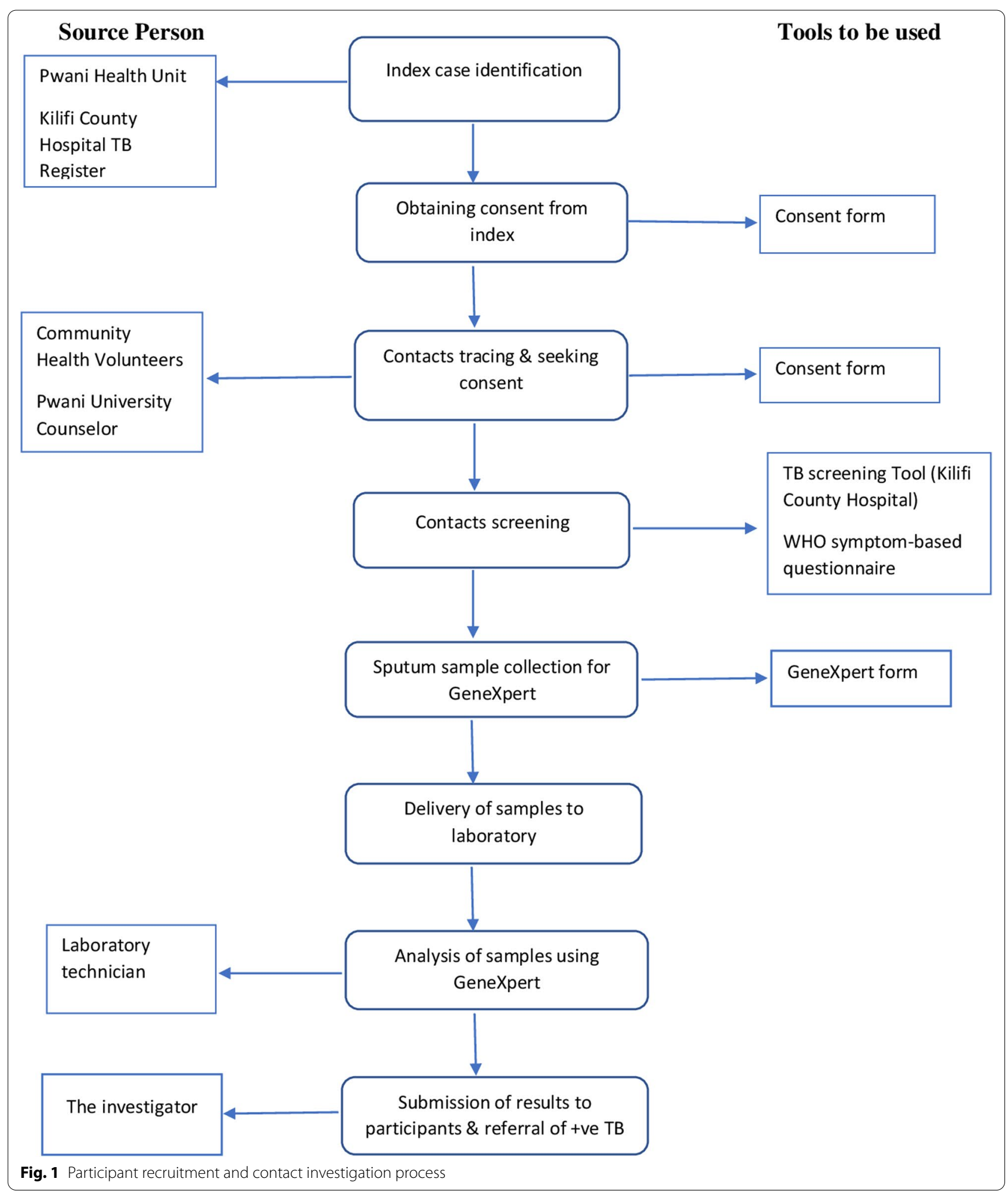

Step 1: We selected index students directly from the sub-county TB coordinator or the university health facility staff who routinely notified the investigator of students receiving treatment or recently diagnosed. In addition, the national electronic surveillance TB system (TIBU) [19] and hospital paper-based register routinely 
checked for university students. Contact details of the selected students extracted from TIBU and validated at the university health facility.

Step 2: We recruited index students with up to three mobile calls or text messages to introduce the study and arrange a face-to-face meeting in the students' chosen venue. Participants excluded from the study if they fail to respond to the third attempt to contact. Written informed consent conducted and patients asked to provide details of their hostel and/or close social contacts during a face-to-face interview using a structured paperbased questionnaire.

Step 3: Student contacts recruited as per index cases using text messages and mobile phone calls to set up interviews. After informed consent obtained, we adopted the WHO standardised symptom-based questionnaire to interview and collect demographic and clinical data from all consenting student contacts [6]. The limited resources for this study prevented contacts obtaining a chest radiography as an additional TB screening test. Sputum samples obtained from all contacts after provision of a routine specimen tube and guided to produce an early morning sputum sample. The sputum collection guide provided to all contacts included taking a deep breath and holding air for at least 5 seconds repeatedly for a few minutes before coughing to encourage sputum to into the mouth before spitting into the sample collection cup. The contacts advised to collect sputum early in the morning on waking. Collaboration with the public TB sub-county coordinator, community health volunteers $(\mathrm{CHV})$, and the study hospital TB laboratory technologist was a central part of our tracing and testing strategy.

\section{Sample analysis in the laboratory}

The hospital laboratory technician received the sputum specimens throughout the 2-year data collection period. The quality of each sputum sample assessed by the laboratory technician before registering the contact details within the routine sputum specimen hospital logbook. Poor-quality samples, including containing saliva instead of sputum discarded and a second specimen requested from the contact. In the laboratory, the standard procedure for sample processing was as follows: the cartridge containing the mixture are placed in the GeneXpert machine which processed the specimen automatically to detect Mycobacterium tuberculosis complex (MTBC) in the sample. If the GeneXpert machine found a positive result for MTBC a result was also provided on whether it was resistance to the standard TB treatment rifampicin. If the result stated 'invalid', the sputum test was repeated with a fresh sample in the GeneXpert machine. The student contacts received the negative GeneXpert results automatically by Short Message Service (SMS). However all positive $\mathrm{TB}$ tests communicated directly to the student contact by TB sub-county coordinator, as per national policy and started on treatment immediately.

\section{Statistical methods}

Data were recorded on standardised questionnaires and register books. Data were later coded and entered into Epinfo database. Statistical analyses were performed using the statistical package for social sciences (SPSS) version 25 and $R$ statistical software version 3.4.1 for windows. Descriptive summaries were used to describe the TB patients and contacts demographic and clinical characteristics. We tested for difference in participants' features between contacts who tested positive and negative for TB using Chi-square/fisher's exact test as appropriate. However, because this method only tests for difference and not effect of individual feature, we performed secondary analysis using log-binomial regression model albeit with low statistical power. We performed univariate log-binomial regression for all the features and used backwards stepwise approach to select features to retain in the multivariable regression model reporting only features with a $P<0.05$. The contacts age and gender were considered as a priori confounders and retained in the final multivariable model. We assessed the multivariable regression model performance and goodness of fit using area under receiver operating characteristic curve (AUC) and Hosmer-Lemeshow test, respectively. For the regression analysis, risk ratio (RR) with $95 \%$ confidence intervals $(\mathrm{CI})$ was reported. In this study, the number of index cases were fixed to those students diagnosed with $\mathrm{TB}$ during study period, therefore no formal sample size was estimated. We adopted an exploratory approach where we did not limit the number of contacts each index case could make.

\section{Results \\ Recruitment and characteristics of index students}

From January 2016 to December 2017 a total of 65 students were identified as index TB cases on treatment from $\mathrm{KCH}$. Of these 65 index TB cases 8 (12\%) were not within the study area. Among the eligible index students $6(11 \%)$ refused to consent therefore we recruited 51 (89\%) into the study (Fig. 2). The index students' median (IQR) age was 21 [20-23] years, and $31(61 \%)$ were males. A total of $43(84 \%)$ of these 51 index students were offcampus residents, 50 (98\%) were new TB cases and 47 (92\%) diagnosed with pulmonary TB. Diagnosis using GeneXpert was reported by $22(43 \%)$ of the TB index students. Only 1 (1.9\%) student with TB was co-infected with HIV while $42(82 \%)$ of the TB index students were self-referrals. By the end of the study, a total of $10(20 \%)$ index TB students had completed treatment, 38 (74\%) 
Table 1 Demographic and clinical characteristics of TB index cases

\begin{tabular}{|c|c|c|}
\hline & $N(51)$ & (\%) \\
\hline \multicolumn{3}{|l|}{ Demographic characteristics } \\
\hline Age, median (IQR) years & $21(20-23)$ & \\
\hline \multicolumn{3}{|l|}{ Gender N (\%) } \\
\hline Male & 31 & 61 \\
\hline Female & 20 & 39 \\
\hline \multicolumn{3}{|l|}{ Residence N (\%) } \\
\hline In-campus (IC) & 8 & 16 \\
\hline Off-campus (OFC) & 43 & 84 \\
\hline \multicolumn{3}{|l|}{ Clinical characteristics } \\
\hline \multicolumn{3}{|l|}{ Type of patient N (\%) } \\
\hline New & 50 & 98 \\
\hline $\mathrm{TFL}^{\#}$ & 1 & 1.9 \\
\hline \multicolumn{3}{|l|}{ Type of TB N (\%) } \\
\hline $\mathrm{EPTB}^{\$}$ & 4 & 7.8 \\
\hline PTB $^{\%}$ & 47 & 92 \\
\hline \multicolumn{3}{|l|}{ Method of diagnosis N (\%) } \\
\hline X-ray & 29 & 57 \\
\hline GeneXpert & 22 & 43 \\
\hline \multicolumn{3}{|l|}{ Index HIV status N (\%) } \\
\hline Negative & 50 & 98 \\
\hline Positive & 1 & 1.9 \\
\hline \multicolumn{3}{|l|}{ Referred by N (\%) } \\
\hline Community health volunteer (CHV) & 1 & 1.9 \\
\hline Private sector (PS) & 8 & 16 \\
\hline Self-referral (SR) & 42 & 82 \\
\hline \multicolumn{3}{|l|}{ Outcome of treatment $N(\%)$} \\
\hline Cured (C) & 38 & 74 \\
\hline Transferred out (TO) & 3 & 5.9 \\
\hline Treatment completed (TC) & 10 & 20 \\
\hline
\end{tabular}

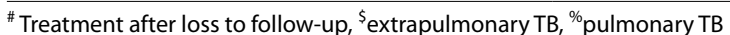

had been confirmed as cured while $3(6 \%)$ were still on treatment (Table 1).

\section{Recruitment and characteristics of TB student contacts}

We recruited all 156 contacts identified by the 51 index TB students (Fig. 2). We report a high participation rate of student indexes $51 / 57$ (89\%) and contacts $156 / 156$ (100\%). Their median (IQR) age was 23 [20-23] years, 80 (51\%) were male and $76(49 \%)$ were household contacts. In total, 120 (77\%) of the contacts were off-campus residents and $46(29 \%)$ described as spending all their time with the index TB cases. Cough, fever, weight loss, sweating at night and swelling at neck/armpits/groin were present amongst 86 (53\%), 60 (39\%), 69 (44\%), 48 (31\%) and $27(17 \%)$ of the contacts, respectively. Only 3 (1.9\%) of the contacts were HIV infected and $9(5.8 \%)$ of the contacts had an underlying medical condition, including asthma and diabetes (Table 2).

\section{Prevalence of TB among student contacts}

Of the 156 student contacts with index TB cases, 5 [3.2\% (95\% CI 1.0-7.3\%)] tested positive for TB using GeneXpert. As per national recommendations, a further eight clinical TB cases were identified using signs and symptoms indicative of active TB disease, despite the negative GeneXpert results. Therefore, a total of 13 [8.3\% (95\% CI 4.5-14\%)] contacts were infected with TB. All the 13 infections were from index cases diagnosed using GeneXpert. The distribution of contact type, age, sex, relation to index case, sleeping in the same and time spent with index case were not different between the five contacts with a positive GeneXpert test result and those with no TB found (Fisher's exact $P$-value $>0.05$ ). We found evidence of significant distribution of sharing a bed with index case between contacts with and without TB (Fisher's exact $P=0.003$ ) (Table 3$)$. However, among the 13 TB cases (GeneXpert test positive/clinical diagnosis) the distribution of all the demographics and contact features were not significantly different (all $P$-values $>0.05$ ) (Table 3).

\section{Associated factors with TB infection}

In the univariate log-binomial regression models, sharing a bed was significantly associated with being diagnosed with TB using GeneXpert among the contacts. Contact type, age, sex, time spent with index case and clinical signs were not associated with being diagnosed with $\mathrm{TB}$ among the contacts. However, sleeping in the same room with an index case and fever had a borderline association with being diagnosed with $\mathrm{TB}$ among the contacts ( $P=0.07$ and $P=0.09$, respectively). In the multivariable regression analysis, only sharing a bed with index case; adjusted risk ratio 22.2 (95\% CI 2.45-202), was associated with being diagnosed with TB using GeneXpert among the contacts (Table 4). The multivariable AUC (95\%) was 0.87 (95\% CI 0.72-0.98) and the Hosmer-Lemeshow test value was 4.59 and $P=0.80$. However, among the 13 GeneXpert test positive/clinical diagnosed cases, fever [aRR 18.4 (95\% CI 2.38-141)] and underlying medical conditions [aRR 4.46 (95\% CI 1.14-17.5)] were associated with TB transmission in multivariable model.

\section{Discussion}

The study performed an active TB contact case finding approach to recruit university students with TB infection and trace and test their hostel and social contacts to explore TB transmission. The community-based 'trace and test' approach implemented in this study also identified significant levels of clinical signs and symptoms and 


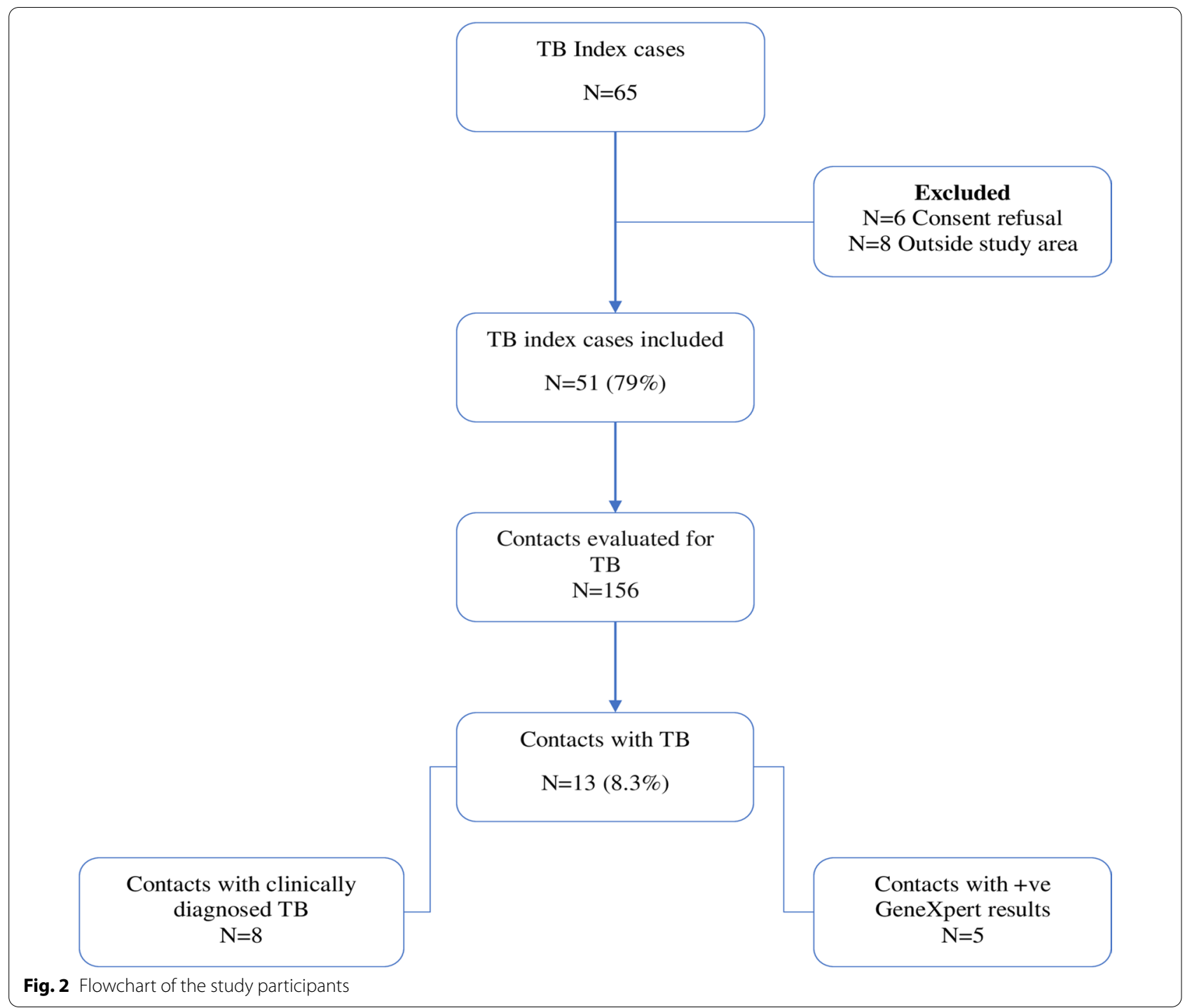

laboratory evidence of TB among the contacts. The inclusion of only one government health facility to identify index cases within the county and high infection levels highlights the importance of university students in $\mathrm{TB}$ transmission.

Our overall (both clinical and GeneXpert) estimated TB prevalence was more than twice as high at $8.3 \%$ compared to the pooled prevalence of active TB (all forms) among close contacts of $3.1 \%$ and $4.5 \%$ reported in two comprehensive meta-analyses, one of which included 95 contact investigation studies in resource limited countries $[9,23]$. Our confirmed TB prevalence of $3.2 \%$ describes a higher prevalence compared to the $1.2 \%$ among adults reported in India [24] and 1.5\% in a comparative meta-analysis study in eleven high burden countries [25]. Our overall (all forms) prevalence was also slightly higher than the prevalence of $6 \%$ reported in a
Ugandan study which included both clinical and bacteriologically defined TB [26]. The difference in prevalence of TB among the contacts in our study would suggest higher risk among student population compared to the general population. The small-scale nature of this study, however, suggests this student population is at high-risk of contracting TB infection. We found more than fifty percent of the TB diagnosis confirmed empirically or without bacteriological confirmation reflecting the current clinical practices in our setting [27]. Our study found students sharing a bed were associated with high risk of contracting TB. However, this finding should be considered cautiously in view of the low statistical power of the study. Similarly, a study of risk factors for TB among close contacts reported that sharing a bedroom with an index case increased exposure to TB perhaps due to enhanced contact during the night, shared airspace, and sharing of 
Table 2 Demographic and clinical characteristics of contacts

\begin{tabular}{|c|c|c|}
\hline & $N(156)$ & (\%) \\
\hline \multicolumn{3}{|l|}{ Demographic characteristics } \\
\hline Age, median (IQR) years & $23(20-23)$ & \\
\hline \multicolumn{3}{|l|}{ Contact type $N(\%)$} \\
\hline Household & 76 & 49 \\
\hline Social & 80 & 51 \\
\hline \multicolumn{3}{|l|}{ Gender N (\%) } \\
\hline Male & 80 & 51 \\
\hline Female & 76 & 49 \\
\hline \multicolumn{3}{|l|}{ Residence $N(\%)$} \\
\hline In-campus (IC) & 36 & 23 \\
\hline Off-campus (OFC) & 120 & 77 \\
\hline \multicolumn{3}{|c|}{ Time spent in the same room with index case $N(\%)$} \\
\hline All time & 46 & 29 \\
\hline Night only & 42 & 27 \\
\hline Day only & 62 & 40 \\
\hline Others & 4 & 3.8 \\
\hline \multicolumn{3}{|l|}{ Clinical characteristics N (\%) } \\
\hline Coughing $\geq 2$ weeks & 86 & 53 \\
\hline Fever & 60 & 39 \\
\hline Had weight loss & 69 & 44 \\
\hline Drenching night sweats & 48 & 31 \\
\hline Swelling at neck/armpits/groin & 27 & 17 \\
\hline \multicolumn{3}{|l|}{ HIV test results } \\
\hline Positive & 3 & 1.9 \\
\hline Negative & 70 & 45 \\
\hline Unknown/not tested & 83 & 53 \\
\hline Any underlying medical condition & 9 & 5.8 \\
\hline
\end{tabular}

MTB aerosols [28]. Our findings are consistent with earlier studies where the risk of transmission was reported to be related to the duration and proximity of contact with the source case, being in an enclosed space with the source case and the infectivity of the source case [28-30]. It is likely sharing a bed resulted in a longer duration in contact with the index case during the period of infectivity (usually weeks to months before diagnosis) and therefore at the highest risk of contracting TB. One study showed that symptomatic contacts with a TB diagnosis had a comparatively longer duration of symptoms and a greater period of contact with index cases [24]. These findings suggest the duration of symptoms and period of contact with index cases could be important predictors for risk of TB among symptomatic contacts. In the context of this study, students spent a period of an average of 4 months in the same room. The reported variation in yield of participants with TB within contact investigation studies could be influenced by clinical factors including both prevalence of TB or HIV infection. As explored in this study, the design and implementation of studies, including screening strategies to identify and trace contacts and diagnostics methods used, may also affect the number of participants with TB.

We report a high level of student participation in the study among both index cases and their contacts. Despite the small-scale nature of the study a significant contrast in student recruitment was observed compared to the higher refusal rates reported in large-scale cross-sectional and longitudinal studies [20, 21]. The large-scale studies describe a contact-tracing strategy that incurs additional costs associated with home visits and followup of TB contacts. In the Kenyan context, TB is a highly stigmatised disease and is often associated with HIV coinfection mostly because the two diseases share similar symptoms, including weight loss [22]. To address this potential barrier to recruiting the students in this $\mathrm{TB}$ transmission study, we employed the mobile phone tracing and community-based meeting venue. The meeting place for the interview was decided by the participant creating a private space to overcome other hostel or social friends becoming aware of the student inclusion in the study, or their TB diagnosis. Our study suggests that the initial phone call introductions accompanied with private meetings may reduce travel and human resource costs, and potentially increase recruitment rates in largescale studies.

The generalisability of our recommendations to both clinicians diagnosing students and policy-makers in different settings is limited by inclusion of only one university and one TB diagnostic and treatment health facility. Our study findings, however, suggest that this mobile phone-based contact tracing, and community-based screening and testing intervention reduced time and cost to the clinician and the investigator compared to visiting each contacts' home. The cost-benefit of this active TB case finding approach using mobile phone technology and private interview spaces to initiate interviews is not provided in this study however requires further investigation in larger cross-sectional studies or within a routine public health intervention. Our study suggests university hostels are high-risk environments for TB transmission, especially if students share beds. This study further supports the global recommendation for improved ventilation in similar overcrowded settings [31]. Promoting potentially low-cost public health interventions which increase natural ventilation in university settings may contribute to global targets to reduce the TB epidemic occurring in high burden countries. Implications of the study in the university include considering routine screening at the beginning and during each semester.

This cross-sectional study sampled student contacts at a single point within this period and therefore not fully capturing TB transmission from index cases to contacts. 
Table 3 Comparison of contacts with and without GeneXpert-diagnosed TB

\begin{tabular}{|c|c|c|c|c|c|c|}
\hline \multirow[t]{2}{*}{ Demographic characteristics } & \multicolumn{3}{|c|}{ GeneXpert-diagnosed TB $(N=5)$} & \multicolumn{3}{|c|}{$\begin{array}{l}\text { Clinical signs and GeneXpert-diagnosed } \\
\mathrm{TB}(N=13)\end{array}$} \\
\hline & TB & No TB & $P$-value\# & TB & No TB & $P$-value\# \\
\hline \multicolumn{7}{|l|}{ Contact type N (\%) } \\
\hline Household & $4(5.3)$ & $72(95)$ & 0.17 & $6(7.9)$ & $70(92)$ & 0.85 \\
\hline Social & $1(1.3)$ & $79(99)$ & & $7(8.8)$ & $73(91)$ & \\
\hline \multicolumn{7}{|l|}{ Age group N (\%) } \\
\hline$<20$ years & 0 & $24(100)$ & 0.64 & $1(4.2)$ & $23(96)$ & 0.73 \\
\hline $20-25$ years & $5(4.6)$ & $109(95)$ & & $11(10)$ & $98(90)$ & \\
\hline$>25$ years & 0 & $23(100)$ & & $1(4.4)$ & $22(96)$ & \\
\hline \multicolumn{7}{|l|}{ Gender N (\%) } \\
\hline Male & $2(2.5)$ & $78(98)$ & 0.48 & $7(8.8)$ & $73(91)$ & 0.85 \\
\hline Female & $3(4.0)$ & $73(96)$ & & $6(7.9)$ & $70(92)$ & \\
\hline \multicolumn{7}{|l|}{ Relation to index case $N(\%)$} \\
\hline Relative & $1(2.4)$ & $41(98)$ & 0.58 & $2(4.8)$ & $40(95)$ & 0.46 \\
\hline Friend & $2(2.5)$ & $78(98)$ & & $7(8.8)$ & $73(91)$ & \\
\hline Student & 0 & $7(100)$ & & 0 & $7(100)$ & \\
\hline Others* & $2(7.4)$ & $25(93)$ & & $4(15)$ & $23(85)$ & \\
\hline \multicolumn{7}{|l|}{ Time spent with index case $N(\%)$} \\
\hline All time & $3(6.5)$ & $43(94)$ & 0.60 & $5(11)$ & $41(89)$ & 0.73 \\
\hline Night only & $1(2.4)$ & $41(98)$ & & $2(4.8)$ & $40(95)$ & \\
\hline Day only & $1(1.6)$ & $61(98)$ & & $6(9.7)$ & $56(90)$ & \\
\hline Others \% & 0 & $6(100)$ & & 0 & $6(100)$ & \\
\hline Share a bed with index case $N(\%)$ & $4(15)$ & $22(85)$ & 0.003 & $4(15)$ & $22(85)$ & 0.15 \\
\hline Sleep in same room with index $N(\%)$ & $4(7.1)$ & $52(93)$ & 0.06 & $5(8.9)$ & $51(91)$ & 0.84 \\
\hline \multicolumn{7}{|l|}{ Clinical signs N $(\%)$} \\
\hline Coughing $\geq 2$ weeks & $5(6.1)$ & $77(94)$ & 0.06 & $13(16)$ & $69(84)$ & $<0.001$ \\
\hline Fever & $4(6.7)$ & $56(93)$ & 0.07 & $12(20)$ & $48(80)$ & $<0.001$ \\
\hline Had weight loss & $2(2.9)$ & $67(97)$ & 0.98 & $10(14)$ & $59(86)$ & 0.02 \\
\hline Drenching night sweats & $5(10)$ & $43(90)$ & 0.002 & $13(27)$ & $35(73)$ & $<0.001$ \\
\hline Swelling at neck/armpits/groin & $1(3.7)$ & $26(96)$ & 0.98 & $6(22)$ & $21(78)$ & 0.01 \\
\hline Underlying medical conditions & 0 & $9(100)$ & 0.98 & $3(33)$ & $6(67)$ & 0.03 \\
\hline HIV positive & 0 & $3(100)$ & 0.98 & 0 & $3(100)$ & 0.98 \\
\hline
\end{tabular}

\#P-values from Chi-square/Fisher's exact test, ${ }^{*} 18$-roommate, 5-coursemate, 4-boy/girlfriend, \% 1-anytime, 3-once in a while, 1-weekends only, 1-once in a while

It is therefore likely that the transmission rate in this study is a gross underestimation of actual transmission in this population. Future research including a well powered prospective cohort study is suggested to better understand TB transmission among university students.

\section{Study strengths and limitations}

The main strength of this study was our collaboration with the Kilifi County TB Control Programme to facilitate working with clinicians who enabled us to rapidly identify index cases and reducing the number of students omitted from the study. We also worked with community health volunteers (CHV) who helped us navigate the community where students live and aided in the recruitment of index and student contacts residing offcampus. CHV conducted visits with the investigator and assisted in the collection of samples and their delivery to the hospital laboratory. An additional strength is our systematic TB testing of all the contacts using GeneXpert, a technique with reported high sensitivity [32] to detect students with TB compared to other diagnostic methods, therefore reducing the number of missed cases.

Our study is limited by the convenience and operational design using only one source to identify students with TB using routinely collected hospital data. Inclusion of private and health facilities outside Kilifi town was not feasible due to time and resource constraints to conduct a larger study. Therefore, this study captures a limited 
Table 4 Factors associated with contacts being GeneXpert-diagnosed TB infected

\begin{tabular}{|c|c|c|c|c|}
\hline & CRR $(95 \% \mathrm{Cl})$ & $P$-value & $\operatorname{ARR}(95 \% \mathrm{Cl})^{\#}$ & $P$-value \\
\hline \multicolumn{5}{|l|}{ Contact type } \\
\hline Household & Reference & & & \\
\hline Social & $0.24(0.03-2.08)$ & 0.19 & & \\
\hline Age in years & $0.99(0.87-1.12)$ & 0.84 & $1.02(0.87-1.19)$ & 0.84 \\
\hline \multicolumn{5}{|l|}{ Gender } \\
\hline Male & Reference & 0.61 & Reference & 0.66 \\
\hline Female & $1.60(0.26-9.87)$ & & $1.50(0.25-9.02)$ & \\
\hline \multicolumn{5}{|l|}{ Time spent with index case } \\
\hline All time & Reference & & & \\
\hline Night only & $0.35(0.03-3.49)$ & 0.37 & & \\
\hline Day only & $0.23(0.02-2.34)$ & 0.21 & & \\
\hline \multicolumn{5}{|l|}{ Share a bed with index case } \\
\hline No & Reference & 0.006 & Reference & 0.008 \\
\hline Yes & $20.0(2.33-171.8)$ & & $22.2(2.45-202)$ & \\
\hline \multicolumn{5}{|l|}{ Sleep in same room with index case } \\
\hline No & Reference & 0.07 & & \\
\hline Yes & $7.62(0.83-68.90)$ & & & \\
\hline \multicolumn{5}{|l|}{ Clinical signs } \\
\hline Coughing $\geq 2$ weeks & - & & & \\
\hline Fever & $6.40(0.72-57.3)$ & 0.09 & $8.15(0.86-76.8)$ & 0.06 \\
\hline Had weight loss & $0.84(0.14-5.03)$ & 0.85 & & \\
\hline Drenching night sweats & - & & & \\
\hline Swelling at neck/armpits/groin & $1.19(0.13-10.7)$ & 0.87 & & \\
\hline Underlying medical conditions & - & & & \\
\hline HIV positive & - & & & \\
\hline \multicolumn{5}{|c|}{ Model performance and goodness of fit } \\
\hline AUC $(95 \% \mathrm{Cl})$ & & & $0.87(0.72-0.98)$ & \\
\hline Hosmer-Lemeshow test & & & 4.59 & 0.80 \\
\hline
\end{tabular}

CRR crude risk ratio, ARR adjusted risk ratio, "Variables reported are those retained in the multivariable model using stepwise approach with a $P<0.05$, RR and $P$-values are from the Log-binomial regression models, $A \cup C$ area under receiver operating characteristics

proportion of students with a TB diagnosis and therefore under-represents the magnitude of index TB cases within the student population. In addition, limiting the study to one diagnostic test, GeneXpert and a single testing point potentially underestimates the prevalence of TB among the contacts.

Finally, the cross-sectional design limited establishing the sequence of events to explore multiple transmission points between index cases and contacts. We also lacked capacity to perform genome sequencing to confirm index case-contacts transmission.

\section{Conclusion}

Our study identified a high level of TB transmission among university students in contact with the index cases. The sensitive 'tracing and testing' approach may have promoted participation in this population. The study justifies further research to explore the sequence and magnitude of TB transmission among students in overcrowded universities in resource-limited contexts.

\section{Abbreviations}

TB: Tuberculosis; HIV/AIDS: Human Immunodeficiency Virus, Acquired Immunodeficiency Syndrome; BCG: Bacillus Calmette-Guérin; CHV: Community health volunteers; TIBU: Electronic surveillance TB system; WHO: World Health Organization; MTBC: Mycobacterium tuberculosis Complex; SPC: Sample processing control; PCC: Probe check; MTB: Mycobacterium tuberculosis; AUC: Area under curve; RR: Risk ratio; Cl: Confidence intervals; KCH: Kilifi County Hospital; IQR: Interquartile range.

\section{Authors' information}

MT holds MPH and is currently a part-time lecturer at the Department of Public Health, Pwani University, Kilifi County, Kenya. This study was her MPH project. WA is a PhD student at Queen Margaret University, Edinburgh, United 
Kingdom. NM holds Dphil in Epidemiology and works as Programme statistician at KEMRI Wellcome Trust Research Programme, Kilifi, Kenya. OA holds PhD in Epidemiology and is currently the chair of Department of Public Health, Pwani University, Kilifi County, Kenya.

\section{Acknowledgements}

The authors would like to acknowledge participants, Kilifi County Hospital, and Community Health Volunteers for making this study a success.

\section{Authors' contributions}

MT, OA and WA conceived the idea. MT recruited study participants. NM developed the database and conducted statistical analysis. MT drafted the first manuscript which was further developed, reviewed, and approved by all authors. All authors read and approved the final manuscript.

\section{Funding}

This study was funded by the Pwani University Internal Research Grant. The funder had no role in study design, data collection, analysis, interpretation and writing of the manuscript.

\section{Availability of data and materials}

All relevant data are within the manuscript and its Supporting Information files. The study data are available from the supporting materials: S1 Dataset and S2 Dataset.

\section{Declarations}

\section{Ethics approval and consent to participate}

Ethical approval was obtained from the Pwani University Ethical Review Committee (ERC/MSc/002/2017). Clearance to obtain information about the students with TB infection was also obtained from the Kilifi County Hospital administration. Informed consent was obtained from the students before they were enrolled into the study.

\section{Consent for publication}

$$
\text { Not applicable. }
$$

\section{Competing interests}

The authors declare that they have no competing interests.

\section{Author details}

${ }^{1}$ Department of Public Health, School of Health and Human Sciences, Pwani University, P.O Box 196-80108, Kilifi, Kenya. ${ }^{2}$ Institute of Global Health and Development, Queen Margaret University, Edinburgh, UK. ${ }^{3} \mathrm{Clinical}$ Research Department, KEMRI Wellcome Trust Research Programme, Kilifi, Kenya.

Received: 7 October 2021 Accepted: 14 December 2021

Published online: 28 December 2021

\section{References}

1. World Health Organization (WHO). Global tuberculosis report 2020 [Internet]. Geneva, Switzerland; 2020. Available from: https://www.who. int/publications/i/item/9789240013131.

2. Snow KJ, Sismanidis C, Denholm J, Sawyer SM, Graham SM. The incidence of tuberculosis among adolescents and young adults: a global estimate. Eur Respir J. 2018;51(2):1702352. https://doi.org/10.1183/13993003. 02352-2017.

3. Storla DG, Yimer S, Bjune GA. A systematic review of delay in the diagnosis and treatment of tuberculosis. BMC Public Health. 2008:8(1):1-9.

4. Finnie RKC, Khoza LB, van den Borne B, Mabunda T, Abotchie P, Mullen PD. Factors associated with patient and health care system delay in diagnosis and treatment for TB in sub-Saharan African countries with high burdens of TB and HIV. Trop Med Int Heal. 2011;16(4):394-411. https://doi. org/10.1111/j.1365-3156.2010.02718.x.

5. Sullivan BJ, Esmaili BE, Cunningham CK. Barriers to initiating tuberculosis treatment in sub-Saharan Africa: a systematic review focused on children and youth. Glob Health Action. 2017;10(1):1290317. https://doi.org/10. 1080/16549716.2017.1290317.

6. World Health Organization (WHO). Recommendations for investigating contacts of persons with infectious tuberculosis in low- and middleincome countries [Internet]. WHO, editor. World Health Organization. Geneva, Switzerland; 2012. 28-41 p. Available from: https://www.who.int/ tb/publications/2012/contact investigation2012/en/.

7. González-Ochoa E, Brooks JL, Matthys F, Calisté P, Armas L, Van der Stuyft P. Pulmonary tuberculosis case detection through fortuitous cough screening during home visits. Trop Med Int Heal. 2009;14(2):131-5. https://doi.org/10.1111/j.1365-3156.2008.02201.x.

8. Fox GJ, Nhung NV, Sy DN, Hoa NLP, Anh LTN, Anh NT, et al. Householdcontact investigation for detection of tuberculosis in Vietnam. N Engl J Med. 2018;378(3):221-9. https://doi.org/10.1056/NEJMoa1700209.

9. Fox GJ, Barry SE, Britton WJ, Marks GB. Contact investigation for tuberculosis: a systematic review and meta-analysis. Eur Respir J. 2013;41(1):140-56. https://doi.org/10.1183/09031936.00070812.

10. Sandgren A van der WM. ECDC guidance on management of contacts of MDR-TB and XDR-TB patients. Eur Respir J [Internet]. 2012; Available from: https://erj.ersjournals.com/.

11. Marais BJ, Lönnroth K, Lawn SD, Migliori GB, Mwaba P, Glaziou P, et al. Tuberculosis comorbidity with communicable and non-communicable diseases: integrating health services and control efforts. Lancet Infect Dis. 2013;13(5):436-48.

12. Faccini M, Codecasa LR, Ciconali G, Cammarata S, Borriello CR, De Gioia C, et al. Tuberculosis outbreak in a primary school, Milan, Italy. Emerg Infect Dis. 2013;19(3):485-7.

13. Mekonnen A, Petros B. Burden of tuberculosis among students in two Ethiopian universities. Ethiop Med J. 2016;54(4):189-96.

14. Enos M, Sitienei J, Ongango J, Mungai B, Kamene M, Wambugu J, et al. Kenya tuberculosis prevalence survey 2016: challenges and opportunities of ending TB in Kenya. PLoS ONE. 2018;13(12):e0209098. https:// doi.org/10.1371/journal.pone.0209098.

15. Kenya National Bureau of Statistics (KNBS). 2019 Kenya Population and Housing Census Volume 1: Population by County and Sub-County [Internet]. Vol. I, 2019 Kenya Population and Housing Census. 2019. 49 p. Available from: https://www.knbs.or.ke/?wpdmp ro $=2019$-kenya-population-and-housing-census-volume-i-popul ation-by-county-and-sub-county.

16. National AIDS Control Council. Kenya HIV Estimates Report [Internet]. Nairobi, Kenya; 2018. Available from: nacc.or.ke.

17. World Health Organization (WHO). South Africa: WHO and UNICEF estimates of immunization coverage: 2015 revision [Internet]. Geneva, Switzerland; 2016. Available from: https://www.who.int/immunization/ monitoring_surveillance/data/tls.pdf.

18. CDC. Core Curriculum on Tuberculosis [Internet]. National Center for HIV/AIDS, Viral Hepatitis, STD and TP, editor. United States of America: Centers for Disease Control and Prevention; 2013. 19-43 p. Available from: www.cdc.gov/tb.

19. Abdullahi OA, Ngari MM, Sanga D, Katana G, Willetts A. Mortality during treatment for tuberculosis; a review of surveillance data in a rural county in Kenya. PLoS ONE. 2019;14(7):e0219191. https://doi.org/10. 1371/journal.pone.0219191.

20. Kigozi NG, Heunis JC, Engelbrecht MC. Yield of systematic household contact investigation for tuberculosis in a high-burden metropolitan district of South Africa. BMC Public Health. 2019;19(1):867.

21. Mekonnen A, Collins JM, Aseffa A, Ameni G, Petros B. Prevalence of pulmonary tuberculosis among students in three eastern Ethiopian universities. Int J Tuberc Lung Dis. 2018;22(10):1210-5. https://doi.org/ 10.5588/ijtld.18.0029.

22. Wambura G, Id M, Nyamogoba HDN, Chiang SS, Mcgarvey T. Burden of stigma among tuberculosis patients in a pastoralist community in Kenya: a mixed methods study. PLoS ONE. 2020;15(10):1-14. https:// doi.org/10.1371/journal.pone.0240457.

23. Morrison J, Pai M, Hopewell PC. Tuberculosis and latent tuberculosis infection in close contacts of people with pulmonary tuberculosis in low-income and middle-income countries: a systematic review and meta-analysis. Lancet Infect Dis. 2008;8(6):359-68.

24. Gupta M, Saibannavar AA, Kumar V. Household symptomatic contact screening of newly diagnosed sputum smears positive 
tuberculosis patients - an effective case detection tool. Lung India. 2016;33(2):159-62

25. Blok L, Sahu S, Creswell J, Alba S, Stevens R, Bakker MI. Comparative MetaAnalysis of Tuberculosis Contact Investigation Interventions in Eleven High Burden Countries. PLoS ONE. 2015;10(3):e0119822. https://doi.org/ 10.1371/journal.pone.0119822.

26. Guwatudde D. Tuberculosis in household contacts of infectious cases in Kampala, Uganda. Am J Epidemiol. 2003;158(9):887-98. https://doi.org/ 10.1093/aje/kwg227.

27. Abdullahi O, Moses N, Sanga D, Annie W. The effect of empirical and laboratory-confirmed tuberculosis on treatment outcomes. Sci Rep. 2021;11(1):14854.

28. Reichler MR, Khan A, Sterling TR, Zhao H, Chen B, Yuan Y, et al. Risk factors for tuberculosis and effect of preventive therapy among close contacts of persons with infectious tuberculosis. Clin Infect Dis. 2020;70(8):1562-72.

29. Fok A, Numata Y, Schulzer M, FitzGerald MJ. Risk factors for clustering of tuberculosis cases: a systematic review of population-based molecular epidemiology studies. Int J Tuberc Lung Dis. 2008;12(5):480-92.

30. Greenaway C, Palayew M, Menzies D. Yield of casual contact investigation by the hour. Int J Tuberc Lung Dis [Internet]. 2003;7(12 Suppl 3):S479-85.

31. World Health Organization (WHO). Guidelines on tuberculosis infection prevention and control 2019 [Internet]. WHO. Geneva, Switzerland; 2019. Available from: https://apps.who.int/iris/bitstream/handle/10665/ 311259/9789241550512-eng.pdf?ua=1\&ua=1.

32. World Health Organization (WHO). Xpert MTB/RIF implementation manual: technical and operational 'how-to'; practical considerations [Internet]. Geneva, Switzerland; 2014. Available from: https://apps.who. int/iris/handle/10665/112469.

\section{Publisher's Note}

Springer Nature remains neutral with regard to jurisdictional claims in published maps and institutional affiliations.

- fast, convenient online submission

- thorough peer review by experienced researchers in your field

- rapid publication on acceptance

- support for research data, including large and complex data types

- gold Open Access which fosters wider collaboration and increased citations

- maximum visibility for your research: over $100 \mathrm{M}$ website views per year

At BMC, research is always in progress.

Learn more biomedcentral.com/submissions 